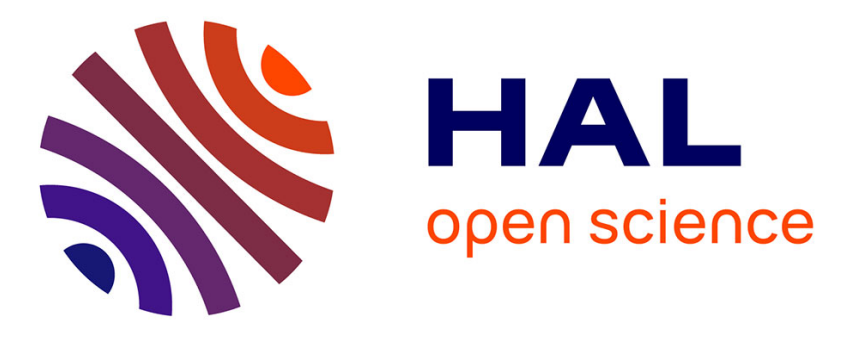

\title{
Towards the Fabrication and Measurement of High Sensitivity SiC-UV Detectors with Oxide Ramp Termination
}

G Brezeanu, Philippe Godignon, E Dimitrova, C Raynaud, Dominique

Planson, A Mihaila, F Udrea, J Millan, G Amaratunga, C Boianceanu

\section{To cite this version:}

G Brezeanu, Philippe Godignon, E Dimitrova, C Raynaud, Dominique Planson, et al.. Towards the Fabrication and Measurement of High Sensitivity SiC-UV Detectors with Oxide Ramp Termination. International Conference on Silicon Carbide and Related Materials (ICSCRM 2003), Oct 2003, Lyon, France. hal-02937545

\section{HAL Id: hal-02937545 \\ https://hal.science/hal-02937545}

Submitted on 14 Sep 2020

HAL is a multi-disciplinary open access archive for the deposit and dissemination of scientific research documents, whether they are published or not. The documents may come from teaching and research institutions in France or abroad, or from public or private research centers.
L'archive ouverte pluridisciplinaire HAL, est destinée au dépôt et à la diffusion de documents scientifiques de niveau recherche, publiés ou non, émanant des établissements d'enseignement et de recherche français ou étrangers, des laboratoires publics ou privés. 


\title{
Towards the Fabrication and Measurement of High Sensitivity SiC-UV Detectors with Oxide Ramp Termination
}

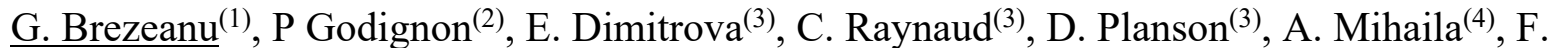

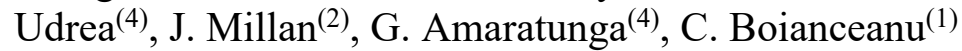 \\ ${ }^{1}$ University "POLITEHNICA” Bucharest, Romania; ${ }^{2}$ Centro Nacional de Microelectrónica, \\ Barcelona, Spain, ${ }^{3}$ Cegely INSA-Lyon, France, ${ }^{4}$ Cambridge University, Cambridge, U.K. \\ Tel: +4021 4024652, Fax:+4021 4024886, brezeanu@mcmca.pub.ro
}

\section{Abstract}

The paper is focused on the fabrication and measurement of the high UV detection performances $6 \mathrm{H}-\mathrm{SiC} p n$ photodiodes with an efficient planar termination. The oxide ramp technology used for these photodetectors is extensively presented. . Two oxide layers with a total thickness of $1 \mu \mathrm{m}$, were grown onto the epilayer. In order to obtain an oxide ramp profile, a suitable etching process was used. Experimental measurements indicate that a ramp angle of less than $4^{\circ}$ was achieved. The $\mathrm{p}^{+}$layer was obtained by $\mathrm{Al}$ implantation. Ni and $\mathrm{Pt}$ were deposited on the back side and on the p layer, respectively. The OBIC technique was used for optical measurements of the samples. The diode's surface was scanned left to right and up to down by a $4 \mu \mathrm{m}$ laser spot modulated at $70 \mathrm{~Hz}$ by a chopper. A computer controls the movement of the test device, and registers the current measurement as a function of the position of the UV spot. The impact of diode's bias as well as their photoresponse on some incident light power values has been revealed by extensive measurements and numerical simulations. The measurement show a stronger diode's bias effect on its optical properties than the simulation data.

We propose this paper for poster presentation at C2 Optical devices and systems 


\title{
Towards the Fabrication and Measurement of High Sensitivity SiC-UV Detectors with Oxide Ramp Termination
}

\author{
G. Brezeanu $^{(1)}$, P Godignon ${ }^{(2)}$, E. Dimitrova ${ }^{(3)}$, C. Raynaud ${ }^{(3)}$, D. Planson ${ }^{(3)}$, A. Mihaila ${ }^{(4)}$,

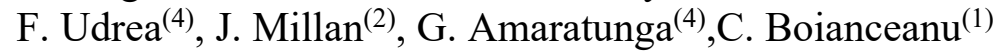 \\ ${ }^{1}$ University "POLITEHNICA" Bucharest, Romania; ${ }^{2}$ Centro Nacional de Microelectrónica, \\ Barcelona, Spain, ${ }^{3}$ Cegely INSA-Lyon, France, ${ }^{4}$ Cambridge University, Cambridge, U.K. \\ Tel: +4021 4024652, Fax:+4021 4024886, brezeanu@mcmca.pub.ro
}

Many of the applications for UV detection involve hostile environments such as in situ combustion monitoring and satellite based missile plume detection, where the ruggedness of $\mathrm{SiC}$ is an important advantage. Other applications capitalize on the sensitivity of wide bandgap semiconductor detectors, such as air quality monitoring and UV exposure dosimetry.

For $\mathrm{SiC}$ diodes we had previously proposed a simple planar edge termination based on a field plate overlapping on oxide ramp at the periphery of the contact. The $p n$ photodetectors, with oxide ramp termination, were realised on $n n^{+} 6 \mathrm{H}-\mathrm{SiC}$ wafer. The $n^{+}$substrate has a typical resistivity of $0.03 \Omega \mathrm{cm}$. The parameters of $n$ epitaxial layer are $x_{e}=8 \mu \mathrm{m}$ and $N_{d}=8.5 \times 10^{15} \mathrm{~cm}^{-3}$. The main technological challenge of the targeted $\mathrm{SiC}$ diode is fabrication of an efficiency oxide ramp termination. In order to obtain different oxide ramp angles various combinations of oxide layers have been deposited on test samples. The wet etching process have been also studied using the standard oxide etch solution and a specific solution containing flourhidric and nitric acids diluted in a large proportion of water. Two oxide ramp profiles, shown in Fig. 1 , have been performed. The first one is a typical ramp oxide termination, (Fig. 1a) while in the second one, the oxide profile, has two ramps (Fig.1b) and corresponds to a two level field plate configuration. This profile, which has been obtained using only a photolitografic step is very attractive for the termination. Two insulating layers comprised of an undoped oxide layer and an $8 \%$ phosphorus doped oxide layer, with a total thickness of $1 \mu \mathrm{m}$, were grown onto the epilayer. Then two steps wet etching were used: an initial etching in a standard oxide etch solution followed by an over-etching in a P-etch solution. Measurements indicated that an oxide ramp termination as in Fig. $1 \mathrm{~b}$ was achieved. The oxide ramp angle is smaller than $4^{\circ}$.

A layout and a cross section of $p n$ detectors with oxide ramp termination are shown in Fig. 2. After oxidation, Ni e-gun evaporation is performed on the heavily doped backside substrate and annealed at $1000^{\circ} \mathrm{C}$ to obtain a good ohmic contact (M3 in Fig. 2.).

The $p^{+}$layer with a surface doping concentration of about $10^{19} \mathrm{~cm}^{-3}$ and a thickness of 0.15 $\mu \mathrm{m}$, was formed by Al implantation. $140 \AA$ platinum was deposited and patterned by lift-off as the ohmic contact on $p^{+}$layer. Platinum (M1 in Fig. 2) is a transparency metal for the photon flux. In order to achieve the same surface potential two layers of $\mathrm{Ti}(1000 \AA)$ and $\mathrm{Al}(1 \mu \mathrm{m})$ were deposited on front-side (M2 in Fig. 2). An antireflection coating (which covers M1) is used to reduce the absorption losses.

For OBIC measurements a $4 \mu \mathrm{m} \mathrm{Ar}^{++}$laser spot with a wavelength in the range from $300 \mathrm{~nm}$ to $363.8 \mathrm{~nm}$, modulated at $70 \mathrm{~Hz}$ by a chopper, was focused on the device. We have realized the measurement by left to right and up to down moving automatically the sample under the laser spot, with a step of $3 \mu \mathrm{m}$. The movement is computer controlled. The output power of the laser is $10 \mathrm{~mW}$ (which corresponds at a incident power density of $0.76 \mathrm{~W} / \mathrm{cm}^{2}$ ) or $20 \mathrm{~mW}$.

Fig 3 presents the measured photocurrent variation as a function UV light position on the sample. The photocurrent peaks increase with the incident light power and reverse voltage of the photodetector. A comparison of measured and simulated data of the photocurrent at different light wavelengths and biases is shown in Fig. 4. The high incident power density used in the simulations $\left(62 \mathrm{~W} / \mathrm{cm}^{2}\right)$, explains the higher current levels from Fig. $4 \mathrm{~b}$. 


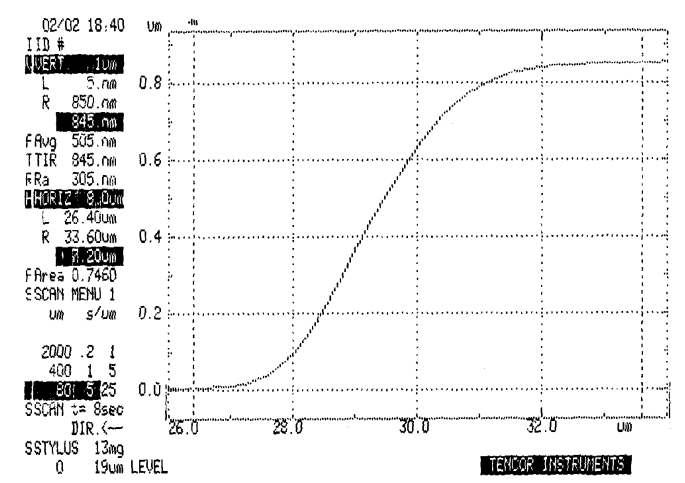

(a)

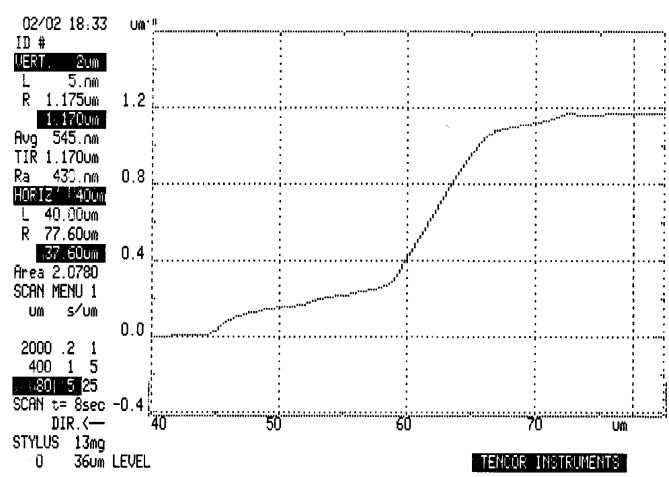

(b)

Fig.1 Two types of oxide ramp termination: (a) with a single ramp and (b) with two ramps.
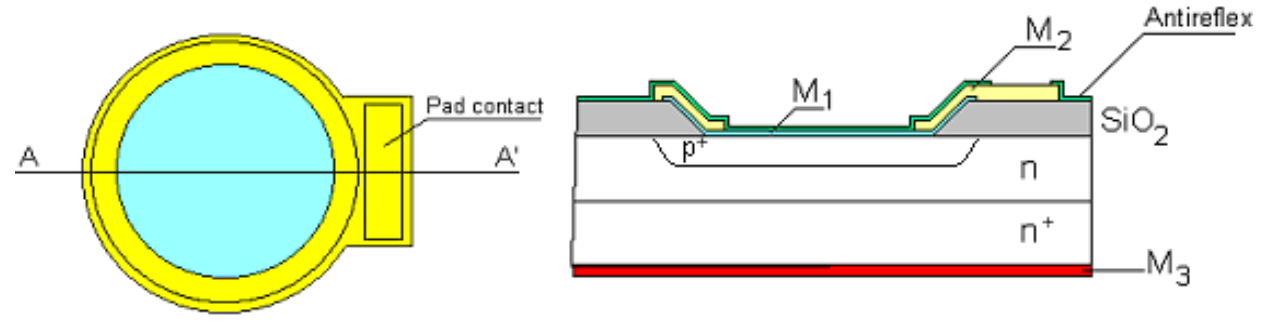

Fig. 2 Layout and cross-section of Schottky photodetector structure.

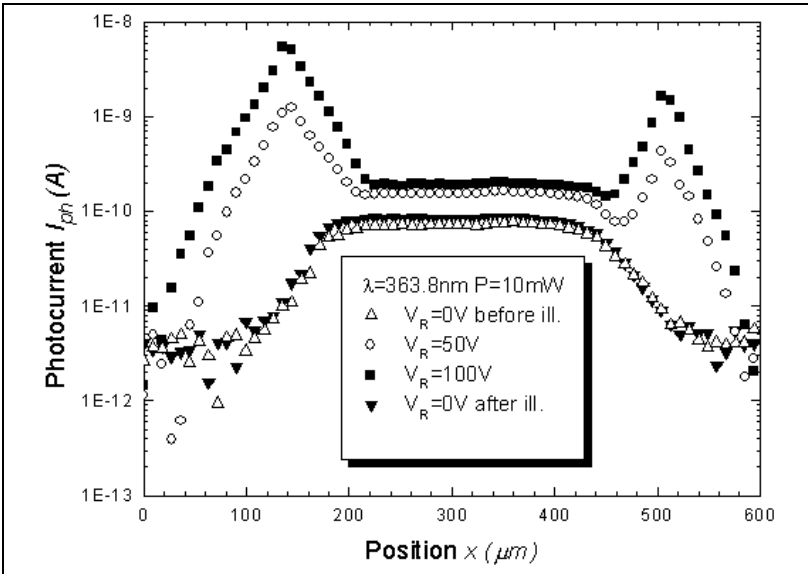

(a)

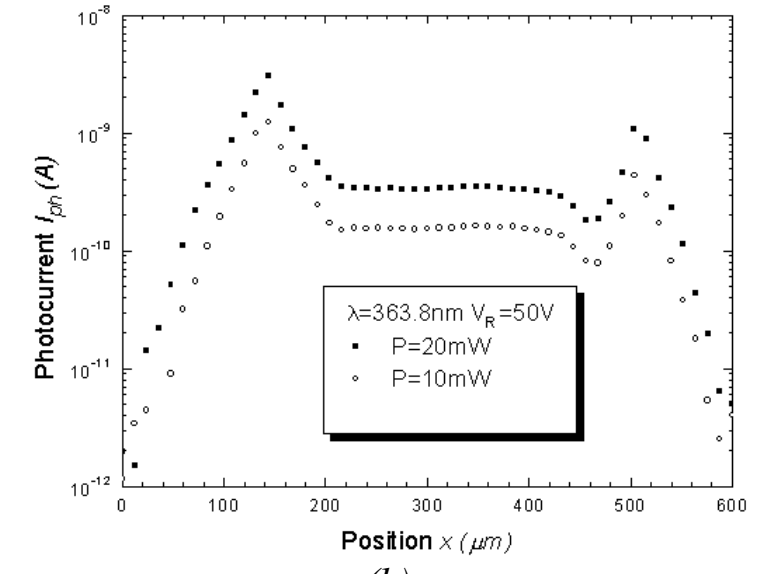

(b)

Fig. $3 J_{\text {ph }}$ measured on pn detectors at $363.8 \mathrm{~nm}$ : (a) bias and (b) incident power effect

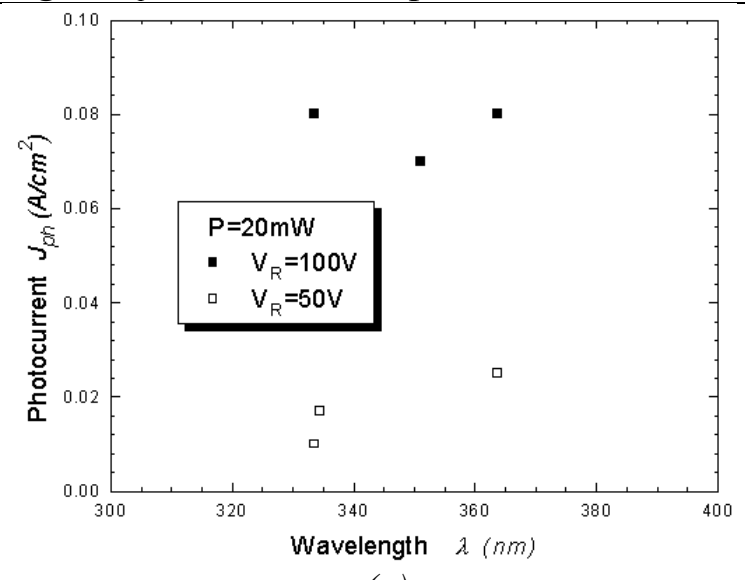

(a)

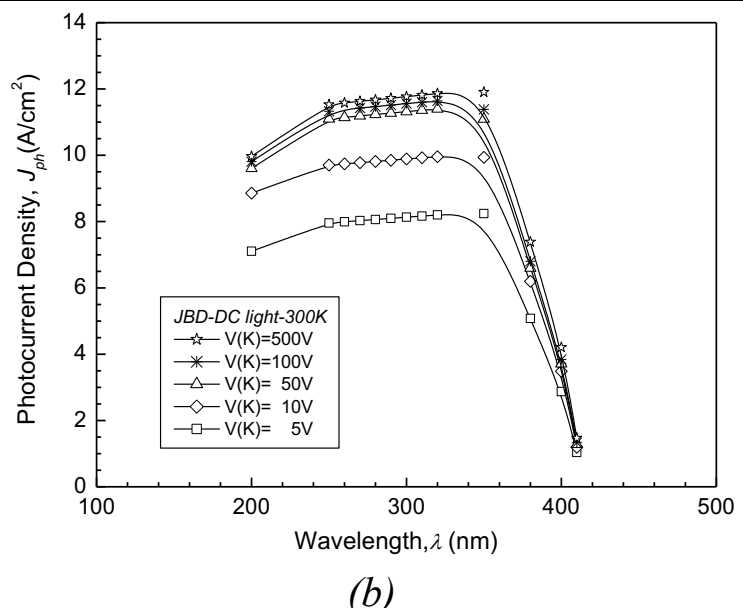

Fig. 4 (a) Measured and (b) simulated photocurrent $v$ s. wavelength for different revers biases 